\title{
Optimized design of a nanostructured SPCE-based multipurpose biosensing platform formed by ferrocene-tethered electrochemically-deposited cauliflower-shaped gold nanoparticles
}

\author{
Wicem Argoubi ${ }^{1}$, Maroua Saadaoui ${ }^{1}$, Sami Ben Aoun ${ }^{*} 2, \S$ and Noureddine Raouafi ${ }^{* 1, \Uparrow}$
}

\author{
Full Research Paper \\ Address: \\ ${ }^{1}$ University of Tunis El-Manar, Chemistry Department, Laboratory of \\ Analytical Chemistry and Electrochemistry (LR99ES15), campus \\ universitaire de Tunis El-Manar 2092, Tunis, Tunisia and ${ }^{2}$ Department \\ of Chemistry, Faculty of Science, Taibah University, PO. Box 30002 \\ Al-Madinah Al-Munawarah, Saudi Arabia \\ Email: \\ Sami Ben Aoun ${ }^{*}$ - sbenaoun@taibahu.edu.sa; Noureddine Raouafi ${ }^{*}$ - \\ n.raouafi@fst.rnu.tn \\ * Corresponding author \\ $\S+966590900727$; Fax.: +966148628023 (Ext. 4326) \\ II +21671872600 (Ext. 273); Fax.: +21671883424 \\ Keywords: \\ cauliflower-shaped gold nanoparticles; enzymatic detection; IgG \\ sensing; nanotechnology; optimized design; screen-printed carbon \\ electrode (SPCE) nanostructuration
}

Beilstein J. Nanotechnol. 2015, 6, 1840-1852. doi:10.3762/bjnano.6.187

Received: 20 March 2015

Accepted: 04 August 2015

Published: 01 September 2015

Associate Editor: N. Motta

(C) 2015 Argoubi et al; licensee Beilstein-Institut. License and terms: see end of document.

\begin{abstract}
The demand for on-site nanodevices is constantly increasing. The technology development for the design of such devices is highly regarded. In this work, we report the design of a disposable platform that is structured with cauliflower-shaped gold nanoparticles (cfAuNPs) and we show its applications in immunosensing and enzyme-based detection. The electrochemical reduction of Au(III) allows for the electrodeposition of highly dispersed cauliflower-shaped gold nanoparticles on the surface of screen-printed carbon electrodes (SPCEs). The nanostructures were functionalized using ferrocenylmethyl lipoic acid ester which allowed for the tethering of the ferrocene group to gold, which serves as an electrochemical transducer/mediator. The bioconjugation of the surface with anti-human IgG antibody ( $\alpha$-hIgG) or horseradish peroxidase (HRP) enzyme yields biosensors, which have been applied for the selective electrochemical detection of human $\mathrm{IgG}(\mathrm{hIgG})$ or $\mathrm{H}_{2} \mathrm{O}_{2}$ as model analytes, respectively. Parameters such as the number of sweeps, amount of charge generated from the oxidation of the electrodeposited gold, time of incubation and concentration of the ferrocene derivatives have been studied using cyclic voltammetry (CV), electrochemical impedance spectroscopy (EIS) and scanning electron microscopy (SEM). Selectivity and specificity tests have been also performed in the presence of potentially interfering substances to either hIgG or $\mathrm{H}_{2} \mathrm{O}_{2}$. Results showed that the devised immunosensor is endowed with good selectivity and specificity in the presence of several folds of competitive analytes. The enzyme-based platform showed a good catalytic activity
\end{abstract}


towards $\mathrm{H}_{2} \mathrm{O}_{2}$ oxidation which predestined it to potential applications pertaining to enzymatic kinetics studies. The levels of hIgG in human serum and $\mathrm{H}_{2} \mathrm{O}_{2}$ in honey were successfully determined and served as assessment tools of the applicability of the platforms for real samples analysis.

\section{Introduction}

Simplicity of design, cost-effectiveness and lightweight are among the most important requirements for the design of devices that can be used for the development of on-site analytical methods [1-3]. Rapid diagnostics in war zones, remote areas or on-field monitoring of warfare agents, explosives, pesticides and herbicides are few among many applications of such a technology. The elaboration of sensors to satisfy these needs is highly regarded $[4,5]$. Screen-printed electrodes on polymeric substrates using various types of conductive inks can be considered as one of the most promising routes for the development of cost-effective, disposable biosensors [4].

Electrochemical (bio)sensors are inherently endowed with several attracting features which are useful for various technological applications [6-8]. Enhancement of their detection capabilities can be easily achieved by modification with various types of nanomaterials to improve the electron-transfer rates between the redox center and the electrode and to procure catalytic effects which allow them in fine to reach the very low concentrations of, e.g., biologically active analytes and diseaserelated biomarkers $[9,10]$. Many electrochemical biosensors use ferrocene to transduce the biological reactions into readily measurable electrical signals $[11,12]$. For instance, Chen and Diao developed a glucose biosensor using gold nanoparticles that were tethered with a $\beta$-cyclodextrin/ferrocene inclusion complex as a transducing system. Connection between gold and the ferrocene host was achieved thanks to a thiol terminal group [13]. The ferrocene complex acted as an electron shuttle allowing for glucose oxidation at low potentials. Li et al. prepared a nanocomposite consisting of reduced graphene oxide hybridized with electrochemically co-reduced gold nanoparticles and ferrocene as a sensitive immunosensor of breast cancer biomarkers [14]. Very recently, Mars et al. showed that the aggregation of gold nanoparticles through a ferrocene-based bipodal ligand allowed for the preparation of a new kind of potential-shifting biosensors working differently from classical FET potentiometric sensors [15]. The system can be used to determine low levels of human immunoglobulin G (hIgG) over a large linear range. Graphene functionalized with ferrocene through a ethylenediamine spacer was prepared by Fan et al. and used as an efficient electron transfer (ET) shuttle to build a sensor for $\mathrm{H}_{2} \mathrm{O}_{2}$ [16]. Also, a nanocomposite formed with ferrocene-branched silica material reduced graphene oxide and glucose oxidase entrapped in chitosan matrix and was used for sensitive glucose determination [17].
In this paper, we report the optimization of the stepwise preparation of disposable SPCE-based biosensors using electrochemically deposited cauliflower-like gold nanoparticles (Figure 1). The optimized platform containing ferrocene-functionalized gold nanoparticles bioconjugated with anti-human IgG antibody or HRP enzyme was used for the detection of hIgG and $\mathrm{H}_{2} \mathrm{O}_{2}$, respectively. The large surface area of the nanostructured electrodes allowed one to detect low concentrations of the analytes. The selectivity and specificity were evaluated against the interference of competitive proteins using a panel of electrochemical techniques such as cyclic voltammetry (CV), differential pulse voltammetry (DPV) and electrochemical impedance spectroscopy (EIS). Application of the two platforms for the detection of hIgG and $\mathrm{H}_{2} \mathrm{O}_{2}$ respectively in human serum and in honey are presented.

\section{Results and Discussion Preparation of the nanostructured platform}

To prepare the gold-nanostructured electrodes, we choose to deposit electrochemically the gold particles directly by reducing gold(III) on the surface of screen-printed carbon electrodes. This method has been very recently used to prepare fractal gold nanostructures for electrodes endowed with very large surface areas useful for the sensitive detection of apolipoprotein E, which is a protein biomarker for Alzheimer's disease [18]. The preparation of the platforms was achieved in a straightforward manner in few steps. Firstly, home-prepared SPCEs were cleaned using a $0.5 \mathrm{M} \mathrm{H}_{2} \mathrm{SO}_{4}$ acid solution to remove the impurities adsorbed on the surface. Five cycles, where the potential was swept from 0.0 to $1.5 \mathrm{~V}$, seemed to be enough to get sufficiently clean surface for gold electrodeposition. This step is crucial in order to get reproducible results. In a second step, the direct electrochemical reduction of a $0.25 \mathrm{mM}$ solution of $\mathrm{Au}(\mathrm{III})$ cations to $\mathrm{Au}(0)$ on the carbon edges allowed for nanostructuring of the surface. Cyclic voltammetry was used to perform this step where the potential was swept from 0.8 to $0.0 \mathrm{~V}$, since gold cations can be easily reduced in this potential window [19]. As it can be seen in Figure 2a, the first cathodic peak ascribed to the reduction of gold cations was observed at ca. $0.15 \mathrm{~V}$ (first cycle). In subsequent cycles ( 2 nd to 15 th) the potential shifted positively (from ca. $0.4 \mathrm{~V}$ to ca. $0.5 \mathrm{~V}$ ) showing that it is much easier to reduce $\mathrm{Au}$ (III) on the nuclei of the formed gold nanoparticles than on the bare carbon substrate [19]. Moreover, using $I-t$ transient current curves (Figure S1, Supporting Information File 1), it was proved that the mecha- 
(a)

(a) $\mathrm{Au}(\mathrm{III}) \mathrm{Au}(\mathrm{III})$
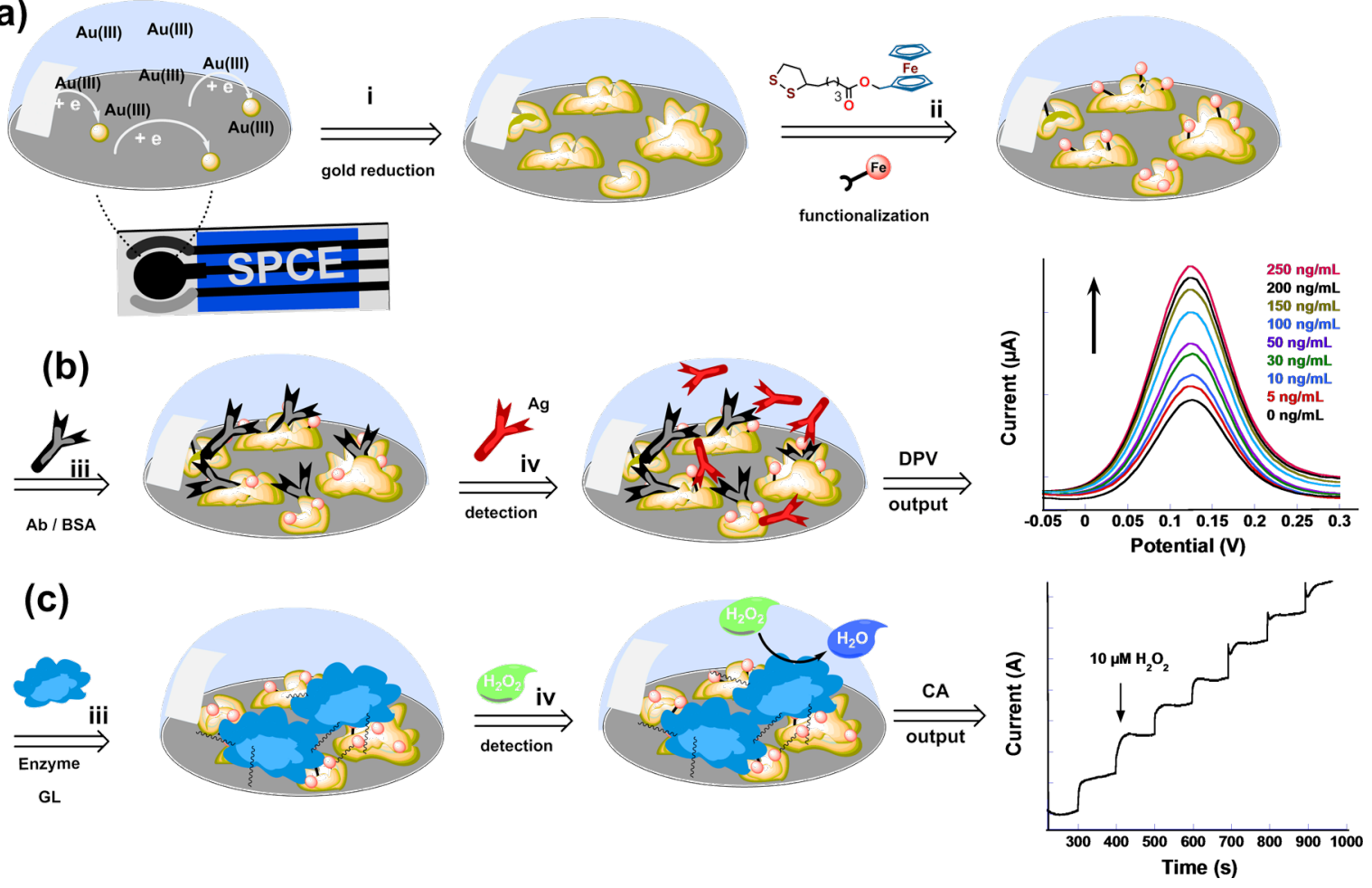

Figure 1: Schematic representation of: (a) the stepwise preparation of the cauliflower-shaped gold nanoparticles-modified SPCEs and their subsequent modification with the ferrocene derivatives, (b) the electrode modification with antibody and hlgG antigen detection by DPV and (c) the electrode modification with HRP enzyme and chronoamperometric detection of hydrogen peroxide.

nism of formation of gold nanoparticles is consistent with a nucleation/growth mechanism [20]. To the best of our knowledge, this is the first case where the nanostructuration is systemically studied in order to optimize the electrodeposition procedure. The gold electrodeposition on SPCE allowed us to obtain a modified electrode with an active surface as large as that of a bulk gold electrode with diameter of $1 \mathrm{~mm}$. The surface calculation was done by assuming the formation of a gold oxide monolayer which is electrochemically reduced by consuming $386 \mu \mathrm{C} / \mathrm{cm}^{2}$ [21-23]. Although using a reduced amount of gold salt, an appreciable surface is obtained at a reduced cost to accommodate a large number of ferrocene derivatives and proteins for the purpose of developing disposable biosensors.

From Figure 2d, we can conclude that the nanoparticles preferrably grow on the edges of the carbon platelets because they contain hydroxyl and carboxyl reactive sites formed during the surface cleaning step [24]. After the electrodeposition, the electrode surface was cleaned with ultrapure water. Cyclic voltammetry performed in a $0.5 \mathrm{M}$ sulfuric acid solution clearly shows two waves, the first one is related to gold oxidation occurring around ca. $1.2 \mathrm{~V}$ and the second one is related to its reduction peak appearing at ca. $0.6 \mathrm{~V}$ [21-23], thus providing proofs of the formation of gold nanoparticles onto the SPCE (cf. Figure 2b). This is further supported by SEM images (Figure 2d-g) and EDX analysis (Figure 2c) confirming that the nanostructuration provokes the formation of small gold nanoparticles which agglomerate into highly dispersed, more complex, cauliflower-shaped gold nanoparticles with the increase of the number of cycles. After 15 cycles, the particulates reach an average diameter of ca. $61 \mathrm{~nm}$.

For electrodes modified by 15 sweeping cycles, EDX showed the presence of ca. $4.7 \%$ of metallic gold on the surface of the SPCE in addition to ca. $2.3 \%$ of oxygen which most probably originated from the terminal carbon oxygenated functions and gold oxides formed by the oxidation of freshly formed nanoparticles. The presence of chlorine (ca. 6.7\%) can be explained by its entrapment between the carbon layers of the working electrode during the voltamperometric process.

\section{Effect of cyclic sweeps on the nanostructured surface}

We further studied the effect of the number of cycles on the final nanostructured surface. For a reduced number of cycles, we observed that the number and size of gold nanoparticles were relatively small (Figure $2 \mathrm{~d}$ and Table S1, Supporting 


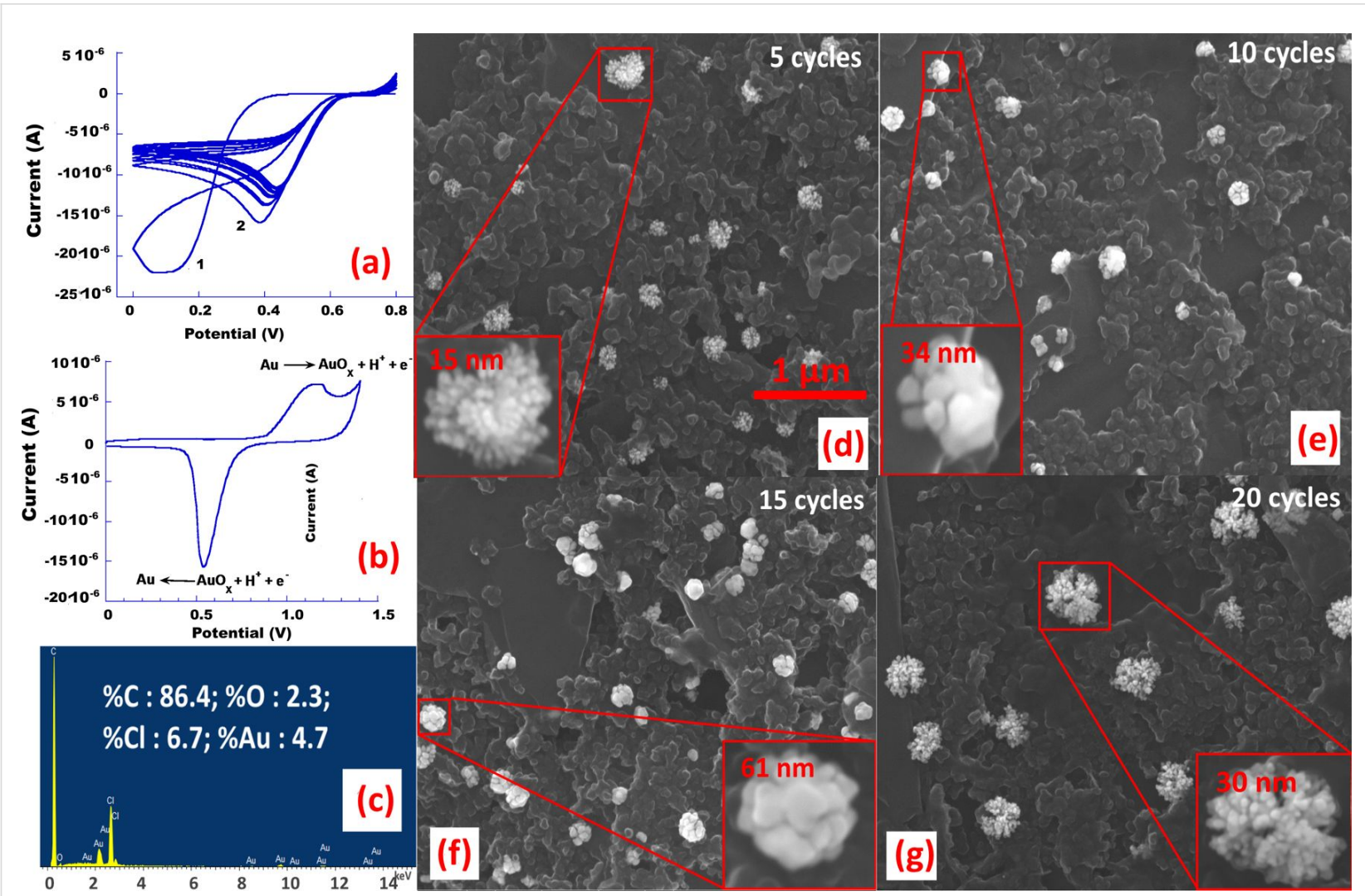

Figure 2: Nanostructuration and characterisation of the SPCE electrode, (a) cyclic voltamperometric deposition of gold nanoparticles from a $0.25 \mathrm{mM} \mathrm{Au}$ (III) solution (out of 15 cycles, only 8 cycles are shown for clarity); (b) Electrochemical oxidation and reduction of electrodeposited gold nanoparticles in a $0.5 \mathrm{M}$ sulfuric acid solution and (c) EDX analysis of the nanostructured SPCE (5 cycles); SEM images of the modified carbon electrodes showing the presence of cauliflower-like gold nanoparticles obtained after: (d) $5 \mathrm{CV}$ cycles, (e) $10 \mathrm{CV}$ cycles, (f) $15 \mathrm{CV}$ cycles and (g) $20 \mathrm{CV}$ cycles. Inset: magnification of gold nanoclusters showing the sizes of the individual nanoparticles (scale $200 \mathrm{~nm}$ ). Scale bar for Figure d-g: $500 \mathrm{~nm}$.

Information File 1). When the number of cycles increased, the density of particles (i.e. the number of nanoparticles per square micrometer) raises rapidly (Figure 2e and Figure 2f) up to 15 cycles, then dramatically decreases for higher number of cycling sweeps because the neighbouring nanoparticles fused into bigger cauliflower-shaped nanostructures as can be observed in Figure 2g. As estimated from the counting of the particles on several SEM micrographs, the approximate size of individual gold nanoparticles increased rapidly from ca. 15 to ca. $61 \mathrm{~nm}$ for 5 to 15 cycles then dropped to ca. $30 \mathrm{~nm}$ thereafter. Probably, the adjacent small gold nanoparticles fused into bigger ones and served as nucleation sites for larger particles. From Table S1 (Supporting Information File 1), the mean number of particles as well as their density is almost the same for 5 and 10 cycles and both increased by almost $50 \%$ after 15 cycles. For more cyclic sweeps, the number and the density of deposited nanoparticles dropped noticeably by $50 \%$, which confirms the fusing of adjacent particles. Thus, we conclude the drastic effect of the cyclic sweeps on the obtained nanostructures which should be carefully optimized before stepping further.

\section{Electrochemical properties of the nanostructured surface}

To further investigate the properties of the modified carbon surface, it was characterized using cyclic voltammetry, chronocoulometry and electrochemical impedance spectroscopy.

\section{Cyclic voltammetric and chronocoulometric studies}

$\mathrm{CV}$ studies showed that the currents generated from gold redox activity are also dependent on the number of cycles as it is depicted in Figure 3a. One can observe both anodic and cathodic currents increase with increasing number of electrodeposition scans. The reduction peak can be used to characterize the quality of gold surface and to measure the active surface area of gold electrodes. During the ongoing scan, gold is oxidized in sulfuric acid to form $\mathrm{Au}(\mathrm{III})$ cations and gold oxide $\left(\mathrm{AuO}_{x}\right)$ species which are reduced to $\mathrm{Au}(0)$ during the backward scan [25]. The amount of charge consumed during the reduction of the oxidized gold can be obtained from the surface integration of the current versus time curves ( $I-t$ curves) derived from the cyclic voltammograms which is a useful tool 

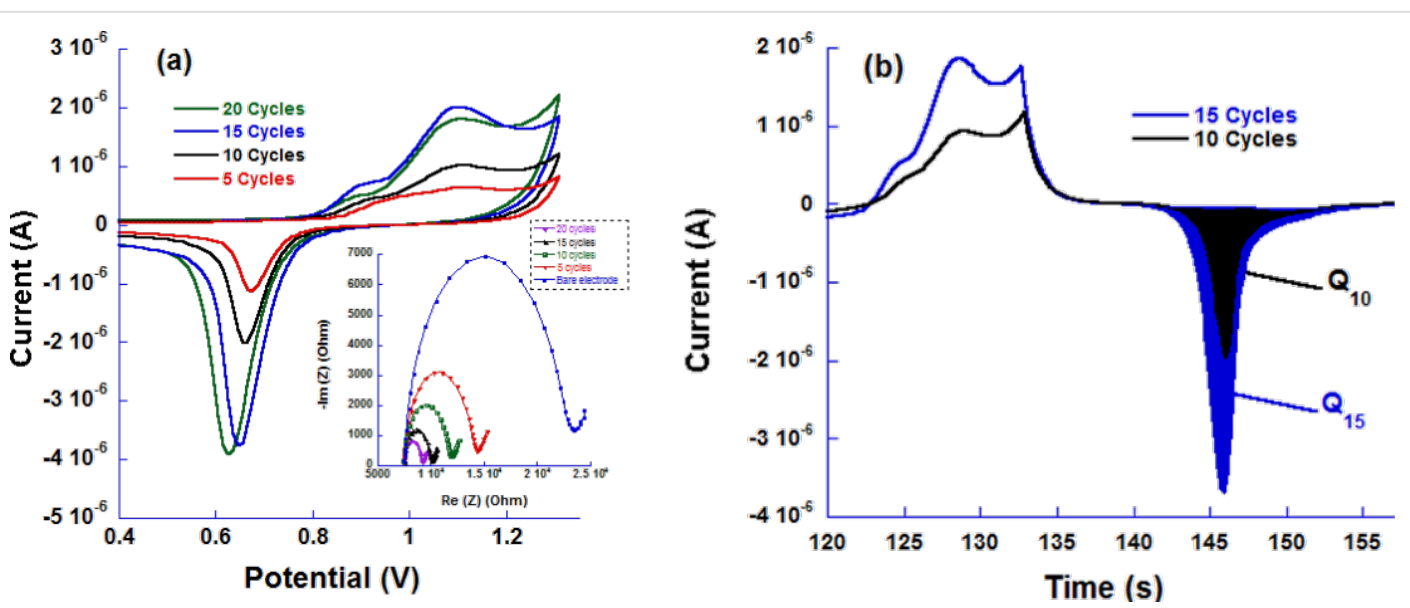

Figure 3: (a) CV curves of four different electrodes nanostructured for 5, 10, 15 and 20 cycles along with the respective Nyquist plots (inset) and (b) $1-t$ curves after baseline correction showing the quantity of charge $(Q)$ determination for 10 and 15 cyclic sweeps.

to estimate the effective sensing area of the as-prepared nanostructured electrodes (Figure 3b) [26].

The amount of charge for different electrodes are summarized in Table 1. We can observe that the amount of charge increases with the increasing number of cycles due to the accumulation of gold on the electrode surface. For instance, the charge quantity nearly doubled from 5 to 10 cycles and same from 10 to 15 cycles (filled areas in Figure 3b). After 20 cycles, it was about four times higher than that obtained for 5 cycles. Although the variation in the density of the as-deposited cauliflower-like gold nanoparticles was not monotonic, we can conclude the observed trend of the quantity of charge is a clear indication that the overall amount of deposited gold increases with increasing number of deposition cycles giving larger active surface areas useful to tether a high number of ferrocene moieties for more sensitive devices.

A number of cyclic sweeps equal to 15 is ideal to obtain a nanostructured surface with high density of well-dispersed nanoparticles and a surface of about $7.8 \times 10^{-3} \mathrm{~cm}^{2}$ corresponding to a $1 \mathrm{~mm}$ diameter bulk gold electrode.

\section{Study by electrochemical impedance spectroscopy}

Gold is a more conductive material than carbon, so the voltamperometric deposition of gold onto the carbon surface is expected to drastically alter its conductivity, which could be easily monitored using faradaic EIS measurements. This is clearly depicted in the Nyquist plots (inset in Figure 3a) of the different electrodes, recorded in the presence of a $5 \mathrm{mM}$ $\left[\mathrm{Fe}(\mathrm{CN})_{6}\right]^{4-} /\left[\mathrm{Fe}(\mathrm{CN})_{6}\right]^{3-}$ solution used to probe the surface conductivity, where the $R_{\mathrm{CT}}$ decreases dramatically upon only a five-cycle deposition and continues to decrease monotonously with an increasing number of performed cycles as a consequence of increasing densities of the deposited gold particles. The outcome of the electrochemical impedance spectroscopy thus corroborates the coulometric studies results (Table 1).

In the present study, a number of 15 cycles was chosen for subsequent investigations since it gave the highest density of cauliflower-like gold nanoparticles with the best surface conductivity. These two parameters are eventually a prelude to larger active surface areas which would allow the tethering of a greater number of ferrocene moieties.

\begin{tabular}{|c|c|c|c|c|}
\hline number of cycles & 5 & 10 & 15 & 20 \\
\hline quantity of charge calculated for the gold reduction / $\mu \mathrm{C}$ & 2.463 & 4.669 & 9.111 & 9.892 \\
\hline$\%$ of $Q$ variation & 0 & $89.6^{a}$ & $269.9^{a}$ & $301.6^{\mathrm{b}}$ \\
\hline$R_{\mathrm{CT}} / \Omega$ & 6915 & 3565 & 2873 & 2611 \\
\hline$\%$ of $R_{\mathrm{CT}}$ variation ${ }^{\mathrm{C}}$ & 0 & 48.5 & 58.4 & 62.2 \\
\hline
\end{tabular}

${ }^{a}$ Calculated as $100 \cdot\left(Q_{j}-Q_{j}\right) / Q_{i}, j=i+5, i=$ number of cycles; ${ }^{\mathrm{b}}$ calculated in relation to 5 cycles; ${ }^{\mathrm{c}}$ calculated as $100 \cdot\left(R^{0} \mathrm{CT}-R_{\mathrm{CT}}^{i}\right) / R^{0} \mathrm{CT}, \mathrm{R}^{0} \mathrm{CT}$ is for 5 cycles and $R_{C T}$ for 10,15 and 20 cycles. 


\section{Immunosensing of human IgG}

The ferrocene derivative $(\mathrm{FcD})$ was obtained by Steglich DMAP-catalyzed esterification between lipoic acid and ferrocene methanol using DCC as a condensing agent according to previously published reports $[15,27]$.

\section{Immunosensor preparation}

It is well known that gold has a high affinity toward sulfurterminated compounds [28]. Several experiments showed that gold nanostructured electrodes should be incubated for at least $6 \mathrm{~h}$ in a $1 \mathrm{mM}$ ferrocene ester solution to get the highest currents of the ferrocene oxidation peaks (Figure S2, Supporting Information File 1). Electrochemically assisted method of lipoic acid deposition was also tested [29] to improve the modification and shorten the incubation time. However, the obtained results from the passive method were better.

Cyclic voltammetry showed a reversible CV profile related to the oxidation of the ferrocene moiety to the ferrocenium cation at ca. $0.14 \mathrm{~V}$ and a reduction peak at ca. $0.09 \mathrm{~V}$. The peak-topeak separation of ca. $50 \mathrm{mV}$ and the $I_{\mathrm{pc}}$-to- $I_{\mathrm{pa}}$ current ratio close to unity suggest that ferrocene keeps its reversibility even when adsorbed onto the gold surface. The slope of the plot representing the logarithm of current versus the logarithm of the scan rate was found to be ca. 0.94 which is close to unity, suggesting an adsorption-controlled process [30], which is consistent with a self-assembled monolayer of alkyl groups bearing terminal electroactive redox centers.

The FcD/cfAuNPs/SPCE were conjugated with the antibody then covered by $3 \%$ BSA to avoid the oxidation of bare cfAuNPs (Figure 4a). The CV curves of FcD prior and after addition of the antibody and BSA have similar shapes with a noticeable decrease in current densities showing that the formation of a protein layer hindered the ET process. Faradic EIS showed that the surface modification by gold induces a dramatic decrease of $R_{\mathrm{CT}}$, which slowly increases after the stepwise modification by ferrocene derivative, the antibody and
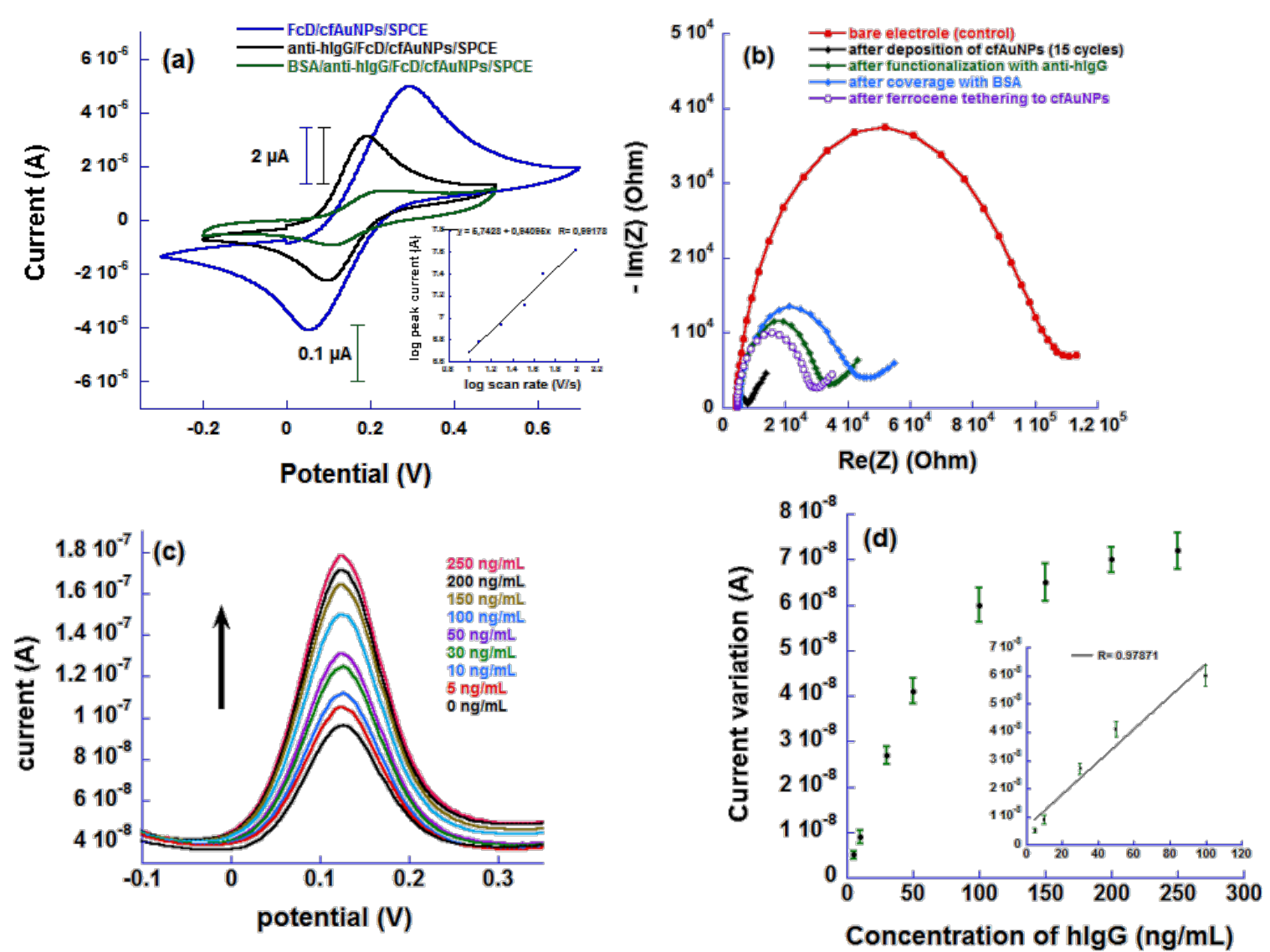

Figure 4: (a) CV curves of functionalization of cfAuNPs by FcD (blue), conjugation with the Ab (black), coverage with BSA protein (green). The inset shows the the logarithm of the peak current as a function of the logarithm of the scan rate, (b) EIS characterization of the stepwise surface modification, (c) Variation of DPV current response upon the antigen addition and (d) Calibration curve for hlgG biosensing (the inset shows the linear concentration range). 
BSA (Figure 4b). In the first step, electrodeposition of gold nanoparticles on the carbon surface provokes a sharp decrease of the surface resistivity because of the higher conductivity of gold. The subsequent self-assembly of the ferrocene derivative induces a roughly 4-fold increase of the surface resistivity because of the total passivation of the gold surface by a sulfur layer. Further modification with the antibody and BSA increases the surface impedance due to the electron transfer from the redox probe present in the solution. Thus, the ferrocene covered by a protein layer can be expected to transduce the recognition event between the antibody and the corresponding antigen $(\mathrm{Ag})$.

As it was described above, this method can be used for the straightforward preparation of bioelectrodes. In this case, the direct deposition of gold nanostructures allowed us to avoid using pre-formed gold nanoparticles and to develop electrodes with a large surface area by forming cauliflowershaped nanoparticles, which can accommodate up to ca. $1.83 \times 10^{12}$ ferrocene molecules. The large number of ferrocene units is expected to result in relatively large currents for a sensitive determination of the analytes and permits to use them for electronic mediation between the enzyme redox center and the electrode surface.

\section{Determination of hlgG levels}

DPV studies showed that successive additions of hIgG aliquots containing known amounts of the antigen to the immunosensor induce current increases of the ferrocene oxidation peak which could attributed to the sensor immunoresponse as a result of an $\mathrm{Ag}-\mathrm{Ab}$ immunocomplex formation (Figure 4c). The DPV current increase continued up to $250 \mathrm{ng} / \mathrm{mL}$ of $\mathrm{hIgG}$ denoting a wide dynamic range and the calibration curve is given in Figure $4 \mathrm{~d}$ (the inset shows the linear range curve). We can speculate that the current increase is due to a larger protein layer that induces an increase of the electron-transfer rate from the ferrocene to the electrode surface through the highly conductive gold nanostructures. The antigen forms a third layer over the deposited gold which probably does not impede the electron transfer since it occurs at the inner ferrocene layer directly linked to the gold. Because during the detection step the number of ferrocene units remains unchanged, the number of electron transferred to the electrode should be the same. Therefore, we can reasonably think that the current increase is due to higher electron-transfer rates resulting from a conformational change of the flexible carbon chain bearing the ferrocene which gets closer to the electrode surface after adding the antigen (i.e., hopping electron-transfer mechanism). Several recent works support the fact the electron-transfer rates can be enhanced by the conformational changes especially of long alkyl chains and biomolecules used to tether ferrocene to a gold surface [31-34].
The current variation stopped at high concentration because of the saturation of all the recognition sites of the immunosensor. The plot of potential variation vs the amount of Ag gives a straight line $\left(\mathrm{R}^{2}=0.97871\right)$ (Figure $4 \mathrm{~d}$ ) which confirmed the reproducibility of the measurements [35]. The limit of detection (LoD) and the limit of quantification (LoQ) were calculated using the formulae $\operatorname{LoD}=\left(3 \times s_{\mathrm{b}}\right) / S$ and $\mathrm{LoQ}=\left(10 \times s_{\mathrm{b}}\right) / S$, respectively, where $s_{\mathrm{b}}$ represents the standard deviation of the blank signal and $S$ represents the sensitivity of the calibration curve. The latter is determined from the slope of the plot of the linear range between 0 and $50 \mathrm{ng} / \mathrm{mL}$ (i.e., ca. $0.82 \mathrm{nA} \cdot \mathrm{mL} / \mathrm{ng}$ ). These limits were estimated to be ca. $0.11 \mathrm{ng} / \mathrm{mL}$ and ca. $0.39 \mathrm{ng} / \mathrm{mL}$, respectively.

The results presented here are in a sharp contrast with those already reported recently by our group [15]. In both cases, ferrocene-modified gold nanoparticles were used. In this particular case, the particles are further tethered to the electrode surface and we observed an amperometric response (current variation) while, when the ferrocene-modified particles were used in colloidal solution, we observed an anodic shift of the ferrocene peak potential which is ascribed to the change in the electrical charge near the ferrocene groups after the addition of antigen. One can conclude that ferrocene is useful as a transducing system to follow biosensing events but foreseeing the exact electrochemical behavior (amperometric vs potentiometric) remains very difficult.

Furthermore, the redox center directly linked to the gold surface, through the formation of a ferrocene-terminated selfassembled monolayer, results in good ET rates from ferrocene to the electrode surface. This property allows using the modified surface to act as a transducer for immunosensing event. More importantly, the ferrocene, being attached to the surface through two gold-sulfur bonds, greatly limits ferrocene leakage into solution and keeps the sensors active. Higher surface coverage allows higher loading in ferrocene and thus widens the dynamic ranges.

\section{Selectivity and specificity of the immune response}

Selectivity and specificity are among the prominent advantages of immunosensors. Several experiments have been undertaken to demonstrate that the observed current response is only ascribed to the immunoresponse. Selectivity and specificity were measured against the interference of BSA and gIgG as competing proteins to the $\mathrm{hIgG}$ analyte. The addition of $30 \mathrm{ng} / \mathrm{mL}$ of $\mathrm{hIgG}$ and $100 \mathrm{ng} / \mathrm{mL}$ from the other proteins had little effect on the oxidation current of ferrocene, which remained almost unchanged compared to the current observed with the same amount of hIgG. In addition, to illustrate the 
immunoresponse specificity, the three proteins were added at once and the resulting DPV current was compared to that obtained from the $\mathrm{hIgG}$ alone. The overall results are summarized in the histogram given in Figure 5a (DPV curves are given in Figure S3, Supporting Information File 1). The small variation in the ferrocene oxidation current could be due the structural similarity between the hIgG and the corresponding antibody gIgG used as an interfering protein. The histogram displayed in Figure $5 \mathrm{~b}$ shows the results from the specificity tests, it can be seen that the addition of a mixture of proteins provokes a strong current increase while in the absence of the specific analyte the current variation is weak denoting a very good specificity of the device. The current rise in the latter case is probably due to structural similarity between $\mathrm{gIgG}$ (i.e., antibody to hIgG antigen produced in goat) and the other immune proteins.

\section{Enzyme-based biosensing}

The oxidoreductase family of enzymes is an important class of enzymes that catalyze redox reactions. They are well-adapted for the construction of electrochemical enzyme-based biosensors for many applications such as blood sugar level measurement, phenol oxidation, and the detection of pesticides and herbicides [36-40]. The second generation enzyme-based biosensors rely on mediators to shuttle electrons from the inner redox moiety of the enzyme to the electrode surface or vice versa. Ferrocene proved to be a good electron mediation agent for such use [13].

\section{Preparation of the enzyme-based sensor}

The biosensor was prepared by simply drop-casting a mixture of the HRP enzyme solution and chitosan as displayed in Figure 1. The chitosan was used as a matrix to retain the enzyme on the nanostructured surface [39]. The stepwise preparation was also characterized using CV and EIS spectroscopy. CV showed an effect similar to the addition of anti- body where the current drops by tenfold after the enzyme casting. $R_{\mathrm{CT}}$ also increased after the enzyme casting, most probably due to the formation of an inhibiting layer of proteins as it was observed for the sequential modification during the preparation of the first biosensor (Figure 6a and Figure 6b).

\section{Selective detection of $\mathrm{H}_{2} \mathrm{O}_{2}$}

The simplicity of design and the ease of layer-by-layer modification make this surface an excellent electrochemical sensing platform for hydrogen peroxide detection. Figure $6 \mathrm{c}$ shows typical chronoamperometric responses of the ferrocene moiety to the successive additions of $\mathrm{H}_{2} \mathrm{O}_{2}$ at an applied potential of $+0.15 \mathrm{~V}$. The inset in Figure 6c shows the linearity of the calibration curve along the different additions of $\mathrm{H}_{2} \mathrm{O}_{2}$ $\left(\mathrm{R}^{2}=0.9989\right)$ with a sensitivity of ca. $4.13 \mathrm{nA} / \mu \mathrm{M}$. The biosensor has a fast response time since the current rapidly reaches a steady state (about $10 \mathrm{~s}$ ). At this potential, the ferrocene is maintained permanently at a reduced state $(\mathrm{Fc})$, meanwhile the enzyme transfers electrons from the ferrocene to the analyte to reduce it. The formed ferrocenium cation $\left(\mathrm{Fc}^{+}\right)$is immediately reduced to its original form since the applied potential corresponds to the ferrocenium/ferrocene reduction potential [41,42]. The novelty in this bioelectrode concept is that the devised system is using a relatively large number of ferrocene units (ca. $1.83 \times 10^{12}$ molecules) tethered to the highly conductive gold material, which results in fast electron-transfer rates from the redox moiety to the electrode surface. Furthermore, the ferrocene vicinity to the HRP enzyme is useful to constantly re-oxidize the enzyme FAD cofactor thus allowing the design of fast response biosensing devices endowed with a large dynamic range.

The LoD and the LoQ were calculated using the same criteria as described earlier for a sensitivity equal to $4.13 \mathrm{nA} / \mu \mathrm{M}$ and a linear range between 0 and $70 \mu \mathrm{M}$. The limits were found to be ca. $0.66 \mu \mathrm{M}$ and ca. $2.20 \mu \mathrm{M}$, respectively, denoting that the

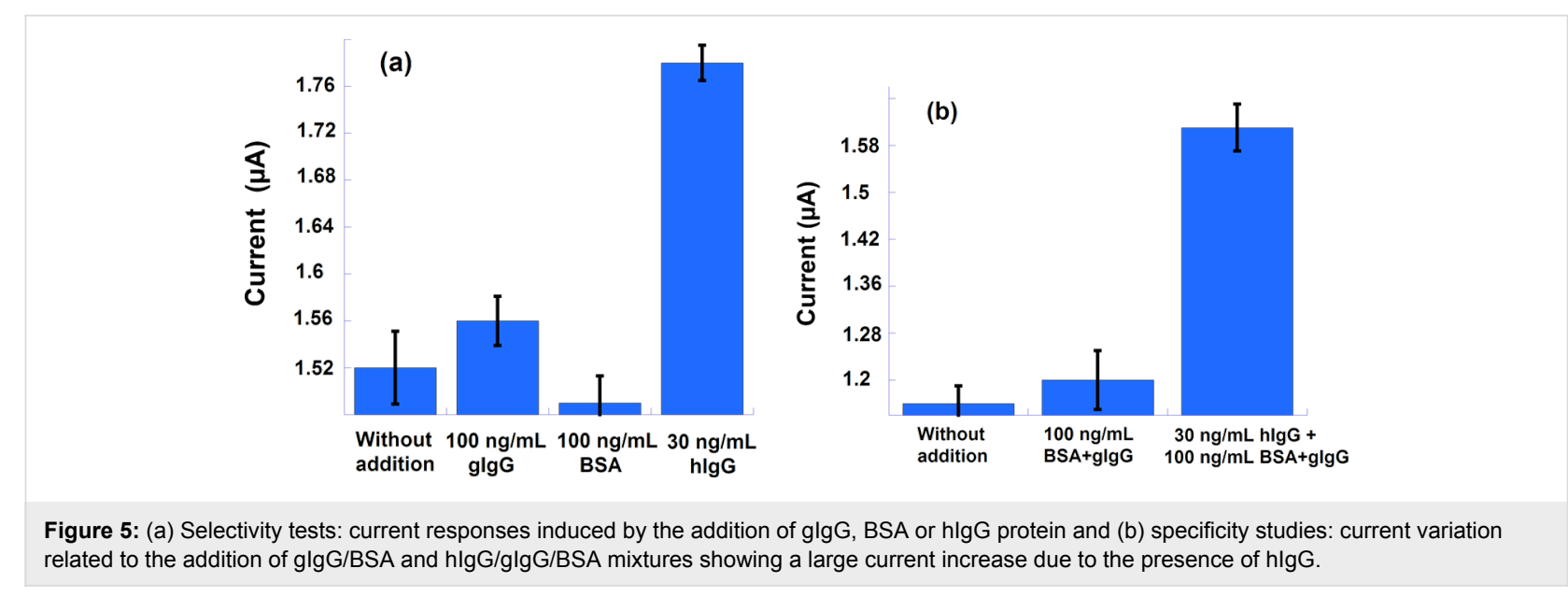



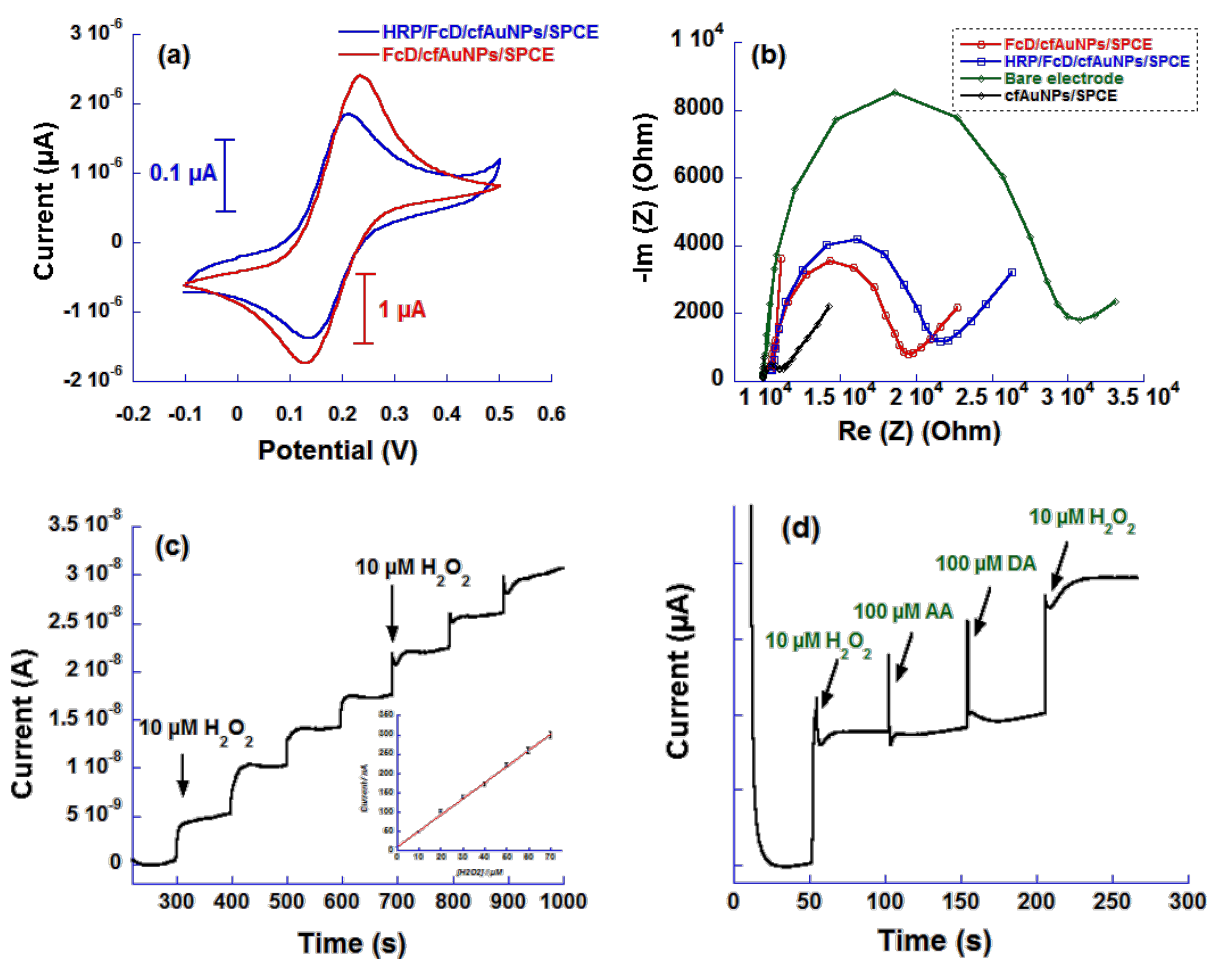

Figure 6: (a) CV curves of functionalized cfAuNPs by the FcD (red) and its conjugation to the HRP enzyme (blue), (b) EIS characterization of the stepwise surface modification, (c) amperometric response of the biosensor to $\mathrm{H}_{2} \mathrm{O}_{2}$ concentrations in a phosphate buffer solution of pH 7.4 at an applied potential of $150 \mathrm{mV}$ (ferrocene reduction potential) upon successive additions of $10 \mu \mathrm{M}$ of $\mathrm{H}_{2} \mathrm{O}_{2}$ at time intervals of $100 \mathrm{~s}$ (inset: experimental data and linear fitting curve) and (d) selectivity study of the enzymatic response in a PBS solution at an applied potential of $290 \mathrm{mV}$ upon successive addition of $10 \mu \mathrm{M}$ of $\mathrm{H}_{2} \mathrm{O}_{2}$ with $100 \mu \mathrm{M}$ of dopamine (DA) and ascorbic acid (AA).

device will be useful to determine sensitively low amounts of hydrogen peroxide at low working potentials comparatively to the direct reduction of $\mathrm{H}_{2} \mathrm{O}_{2}$ (ca. $1.50 \mathrm{~V} / \mathrm{SCE}$ ).

Moreover, the biosensor selectivity was examined using up to the tenfold amount of ascorbic acid and dopamine as interfering agents. From Figure 6d, one can see that the presence of these redox compounds did not significantly alter the amperometric response of the sensor and that is mainly attributed to the low working potential of $+0.15 \mathrm{~V}$.

\section{Comparison with literature}

Table 2 presents the performance results gathered for various immuno- and enzyme-based sensors. Depending on the analyte, $\mathrm{hIgG}$ is usually sought to be detected in picogramm $(\mathrm{ng} / \mathrm{mL})$ levels and hydrogen peroxide in micromolar levels. From the table, we can see that the developed biosensors are more sensitive than most of those recently published in literature using ferrocene or quinone as electron mediators or immunosensing event transducers. The higher sensitivity can be probably ascribed to ferrocene directly attached to the electrode surface. The relatively limited dynamic range is probably due the low number of ferrocene molecules self-assembled to gold nanoparticles (about 0.4 nmole) limiting the turnover frequency during the hydrogen peroxide reduction.

\section{Real sample analysis}

The two devices have been successfully applied to the detection of $\mathrm{hIgG}$ and hydrogen peroxide in human blood serum and local honey [52] chosen as real complex samples, respectively. Before the analysis, the two samples of honey and serum were diluted to $10 \times$ and to $1000 \times$ in order to meet the dynamic ranges of their respective biosensors. The concentrations were measured and the obtained data are summarized in Table 3. Known amounts of hIgG and $\mathrm{H}_{2} \mathrm{O}_{2}$ were then added to the solutions and their concentrations were again measured (Figure S4, Supporting Information File 1). The calculated recovery percentages were found to be in the range of $105.4-106.5 \%$ and $102.0-103.0 \%$ with standard derivations of less than $4.3 \%$ and $3.8 \%$ for human IgG and hydrogen peroxide, respectively [53]. These high recovery values indicate good performances of the $\mathrm{HRP} / \mathrm{FcD} / \mathrm{cfAuNP} / \mathrm{SPCE}$ and the anti-hIgG/FcD/cfAuNPs/ SPCE even for real samples containing high levels of interfering species. 


\begin{tabular}{|c|c|c|c|c|c|}
\hline $\begin{array}{l}\text { modified } \\
\text { electrodes }\end{array}$ & analyte & redox mediator & LoD & dynamic range & reference \\
\hline \multicolumn{6}{|l|}{ detection of hlgG } \\
\hline AuNPs & \multirow{6}{*}{ hlgG } & dopamine & $0.25 \mathrm{ng} / \mathrm{mL}$ & $0.82-90 \mathrm{ng} / \mathrm{mL}$ & [43] \\
\hline $\mathrm{IrO}_{x}^{\mathrm{a}}$ & & hydroquinone & 8.0 & $10-200$ & [44] \\
\hline AuNPs/SPCE & & ferrocene & 9.4 & $50-200$ & {$[15]$} \\
\hline AuNPs/SPCE & & 4-t-butylcatechol & 3.1 & $11-205$ & {$[45]$} \\
\hline Au colloid & & {$\left[\mathrm{Fe}(\mathrm{CN})_{6}\right]^{4-} /\left[\mathrm{Fe}(\mathrm{CN})_{6}\right]^{3-}$} & 4100 & $(15-328) \times 10^{3}$ & {$[46]$} \\
\hline cfAuNPs/SPCE & & ferrocene & 0.11 & $0.11-50$ & this work \\
\hline \multicolumn{6}{|l|}{ detection of $\mathrm{H}_{2} \mathrm{O}_{2}$} \\
\hline $\begin{array}{l}\text { montmorillonite } \\
\text { colloid }\end{array}$ & \multirow{6}{*}{$\mathrm{H}_{2} \mathrm{O}_{2}$} & methylene green & $0.4 \mu \mathrm{M}$ & $2-3000 \mu \mathrm{M}$ & {$[47]$} \\
\hline colloidal Au/ITO & & - & 8.0 & $20-8000$ & {$[48]$} \\
\hline Au colloid & & catechol & 0.15 & $0.4-330$ & [49] \\
\hline $\mathrm{Fc} / \mathrm{CPE}^{\mathrm{b}}$ & & ferrocene & 0.1 & $0.1-10$ & {$[50]$} \\
\hline $\mathrm{Fc} / \mathrm{PAPO} / \mathrm{CPE}^{\mathrm{C}}$ & & ferrocene & - & $0.6-20$ & {$[51]$} \\
\hline cfAuNPs/SPCE & & ferrocene & 0.66 & $0.7-70$ & this work \\
\hline
\end{tabular}

arOx: iridium oxide; ${ }^{b} \mathrm{CPE}$ : carbon paste electrode; ${ }^{\mathrm{CPAPO}}$ : poly(3-aminophenol).

\begin{tabular}{|c|c|c|c|c|}
\hline samples & detected $(P)$ & added (Q) & detected after addition ( $R$ ) & $\%$ recovery $100 \times(R-P) / Q$ (std deviation) \\
\hline \multicolumn{5}{|c|}{ detection of hlgG } \\
\hline \multirow{2}{*}{ serum } & 8.0 & 10 & 18.54 & $105.4 \pm 3.5$ \\
\hline & - & 20 & 29.3 & $106.5 \pm 4.3$ \\
\hline \multicolumn{5}{|c|}{ detection of $\mathrm{H}_{2} \mathrm{O}_{2}$} \\
\hline \multirow[t]{2}{*}{ honey } & 12.9 & 10 & 23.1 & $102.0 \pm 3.6$ \\
\hline & - & 20 & 33.5 & $103.0 \pm 3.8$ \\
\hline
\end{tabular}

\section{Conclusion}

In this work, we showed that the design of a disposable platform structured with cauliflower-like gold NPs (cfAuNPs) can be achieved in a stepwise manner and we tried to find the optimal conditions for its design. In a second step, we successfully applied it for the fabrication of two families of biosensors. The first one is devised for the hIgG immunosensing as a model analyte and the second one for the catalytic detection of $\mathrm{H}_{2} \mathrm{O}_{2}$. Both biosensors rely on ferrocene tethered to the gold nanoparticles to either transduce the recognition event or to catalyze the hydrogen peroxide reduction. The biosensors are endowed with good dynamic ranges, high sensitivities and were found to be selective and specific to the examined analytes. The biosensors were assessed for accurate determination of the analytes in complex matrix formed by human serum and honey. The platform is a prelude to a more specific application in the design of point-of-care and portable devices for use in remote areas and on-field monitoring of several types of analytes such as explosives and other warfare agents.

\section{Experimental \\ Materials and apparatuses}

$\alpha$-Lipoic acid ( $\geq 98 \%$ ), 1-ferrocenylmethanol (97\%), dimethylaminopyridine (DMAP) (99\%), $\mathrm{HAuCl}_{4} \cdot 3 \mathrm{H}_{2} \mathrm{O}$ (99.9\%), dicyclohexylcarbodiimide (DCC) (99\%), sodium nitrate ( $\geq 98 \%$ ), human IgG (hIgG, $\geq 95 \%$ ), polyclonal anti-human IgG antibody $(\alpha$-hIgG), polyclonal anti-human IgG antibody (gIgG, produced in goat), bovine serum albumin (98\%), ascorbic acid, 
dopamine, $\mathrm{H}_{2} \mathrm{O}_{2}$, silica gel 60 mesh and $\mathrm{F}_{254} \mathrm{~nm}$ fluorescent silica-coated aluminum TLC plates were purchased from Sigma-Aldrich (Germany) and used as received without further purification. All solvents used were of analytical grade and were used without further purification. Human blood serum obtained from the blood of healthy persons and honey from the local market were used as real samples for the detection of hIgG and $\mathrm{H}_{2} \mathrm{O}_{2}$, respectively.

All voltammetric experiments (CV and DPV) and EIS measurements were recorded using a Metrohm Autolab PGSTAT M204 electrochemical workstation equipped with an FRA impedance module. Experiments were designed and data collected using Nova ${ }^{\circledR}$ software. Custom-made screen-printed carbon electrodes (SPCEs) printed on polyethylene terephthalate (PET) sheets using a DEK-248 screen printer (DEK International) were employed to perform the electrochemical experiments. Each SPCE comprises of a $3 \mathrm{~mm}$ disk used as a carbon working electrode, a printed $\mathrm{Ag} / \mathrm{AgCl}$ reference electrode and a carbon counter-electrode.

SEM micrographs and energy-dispersive X-ray spectroscopy (EDX) analysis were recorded using a FEI Quanta 650 FEG ESEM scanning electron microscope. NMR spectra were recorded in Bruker Advance 300 apparatus in $\mathrm{CDCl}_{3}$ at $300 \mathrm{MHz}$ frequency. Chemical shifts are given in ppm using tetramethylsilane (TMS) as an internal reference. Deionized water, produced using Milli-Q system (>18.2 M $/ / \mathrm{cm})$ purchased from Millipore Inc., was used for the preparation of all solutions.

\section{Electrochemical measurements}

Voltammetric measurements were carried out in triplicate by casting $25 \mu \mathrm{L}$ of hIgG dissolved in a PBS solution (pH 7.4) on the modified SPCE working electrode. For all the immunosensing experiments, the $\mathrm{CV}$ and DPV curves were measured at a scan rate of $50 \mathrm{mV} / \mathrm{s}$ in the potential range between -0.1 and $0.4 \mathrm{~V}$ prior and after successive additions of $2 \mu \mathrm{L}$ from stock solutions to achieve $5,10,30,50,100,150,200$ or $250 \mathrm{ng} / \mathrm{mL}$ of hIgG on the working electrode surface. For the selectivity tests, $25 \mu \mathrm{L}$ (i.e., $100 \mathrm{ng}$ ) of BSA or $\alpha$-hIgG were cast onto the surface of the biosensor, the DPV current was measured and compared to that obtained for $30 \mathrm{ng}$ of hIgG. Specificity was obtained from comparative measurements of currents obtained for $25 \mu \mathrm{L}$ containing $100 \mathrm{ng}$ of BSA and $30 \mathrm{ng}$ of hIgG and $25 \mu \mathrm{L}$ containing a mixture of the same amount of BSA, $\alpha-\mathrm{hIgG}$ and gIgG.

For EIS measurements, after each step of the SPCE modification, $25 \mu \mathrm{L}$ of a PBS solution containing $5 \mathrm{mM}$ of $\left[\mathrm{Fe}(\mathrm{CN})_{6}\right]^{4-} /\left[\mathrm{Fe}(\mathrm{CN})_{6}\right]^{3-}$ were dropped on the electrode surface and the frequency was swept from $100 \mathrm{kHz}$ to $0.1 \mathrm{mHz}$ at an applied potential of $200 \mathrm{mV}$ with an amplitude modulation of $\pm 20 \mathrm{mV}$.

\section{Preparation of the biosensing platform}

The ferrocene derivative $(\mathrm{FcD})$ was prepared according to literature [15,27]. A $0.25 \mathrm{mM} \mathrm{Au}$ (III) solution in $0.1 \mathrm{M} \mathrm{KNO}_{3}$ was prepared by dissolving $100 \mu \mathrm{L}$ of $0.01 \mathrm{M} \mathrm{HAuCl}_{4}$ and $4.9 \mathrm{mg}$ of $\mathrm{KNO}_{3}$ in $300 \mu \mathrm{L}$ of deionized water. The nanostructuration was performed by cycling the potential from 0.8 to $0.0 \mathrm{~V}$ at $50 \mathrm{mV} / \mathrm{s}$ sweep rate in order to reduce $\mathrm{Au}(\mathrm{III})$ to $\mathrm{Au}(0)$. Separately, $50 \mu \mathrm{L}$ of a $0.1 \mathrm{M}$ ethanolic solution of freshly synthesized $\mathrm{FcD}$ was added to $450 \mu \mathrm{L}$ of a PBS solution to prepare a $10 \mathrm{mM} \mathrm{FcD}$ solution. The nanostructured electrode was incubated in the as-prepared solution for $6 \mathrm{~h}$ to allow the ferrocene tethering to the electrode surface. Finally, to prepare the immunosensor, $5 \mu \mathrm{L}$ of a $10 \mu \mathrm{g} / \mathrm{mL} \alpha$-hIgG antibody solution was cast on the modified surface and allowed to dry at RT for $24 \mathrm{~h}$. The non-adsorbed antibodies were washed away with PBS then ultrapure water and the unmodified gold was blocked by the addition of $5 \mu \mathrm{L}$ of a $3 \%$ BSA solution.

The enzyme-based platform was prepared by drop-casting $5 \mu \mathrm{L}$ of HRP solution $(10 \mathrm{mg} / \mathrm{mL})$ onto the ferrocene-modified cfAuNPs-structured electrode.

Determination of the concentrations of $\mathrm{hIgG}$ and $\mathrm{H}_{2} \mathrm{O}_{2}$ in real samples were performed by DPV and chronoamperometry using the anti-hIgG/FcD/cfAuNPs/SPCE and HRP/FcD/ cfAuNPs/SPCE. To prepare the solutions, 1 and $100 \mu \mathrm{L}$ of serum and honey were respectively dissolved in $1 \mathrm{~mL}$ of PBS solution (30 min sonication is necessary to obtain a homogeneous solution of honey). The concentrations of real samples were determinated using the standard addition method of 10 and $20 \mathrm{ng} / \mathrm{mL}$ of hIgG or 10 and $20 \mu \mathrm{M}$ of $\mathrm{H}_{2} \mathrm{O}_{2}$ consecutively in order to calculate the recovery rates.

\section{Supporting Information}

The Supporting Information features the statistical distribution of gold nanoclusters in dependance of the number of cyclic scans and supplementary electrochemical experiments ( $I-t$ transient curve, current dependence on incubation time and selectivity/specificity test of the immunosensor).

\section{Supporting Information File 1}

Additional experimental data.

[http://www.beilstein-journals.org/bjnano/content/ supplementary/2190-4286-6-187-S1.pdf] 


\section{Acknowledgements}

The authors would like to offer their thanks to the University of Tunis El-Manar for the mobility grants "Bourse d'Alternance" given to WA and MS and the Ministry of Higher Education and Scientific Research for the funding of Lab-CH02 (LR99ES15).

\section{References}

1. Roda, A.; Michelini, E.; Cevenini, L.; Calabria, D.; Calabretta, M. M.; Simoni, P. Anal. Chem. 2014, 86, 7299-7304. doi:10.1021/ac502137s

2. Le, T. T.; Adamiak, B.; Benton, D. J.; Johnson, C. J.; Sharma, S.; Fenton, R.; McCauley, J. W.; Iqbal, M.; Cass, A. E. G. Chem. Commun. 2014, 50, 15533-15536. doi:10.1039/c4cc07888h

3. Kim, J.-H.; Mun, S.; Ko, H.-U.; Yun, G.-Y.; Kim, J. Nanotechnology 2014, 25, 092001. doi:10.1088/0957-4484/25/9/092001

4. Matatagui, D.; Fernández, M. J.; Fontecha, J.; Santos, J. P.; Gràcia, I.; Cané, C.; Horrillo, M. C. Sens. Actuators, B 2012, 175, 173-178. doi:10.1016/j.snb.2012.02.061

5. Pérez-López, B.; Merkoçi, A. Trends Food Sci. Technol. 2011, 22, 625-639. doi:10.1016/j.tifs.2011.04.001

6. Li, Y.; Xu, J.; Sun, C. RSC Adv. 2014, 5, 1125-1147. doi:10.1039/c4ra13080d

7. Janegitz, B. C.; Cancino, J.; Zucolotto, V. J. Nanosci. Nanotechnol. 2014, 14, 378-389. doi:10.1166/jnn.2014.9234

8. Siangproh, W.; Dungchai, W.; Rattanarat, P.; Chailapakul, O. Anal. Chim. Acta 2011, 690, 10-25. doi:10.1016/j.aca.2011.01.054

9. Tang, D.; Cui, Y.; Chen, G. Analyst 2013, 138, 981-990. doi:10.1039/c2an36500f

10. Du, D.; Zou, Z.; Shin, Y.; Wang, J.; Wu, H.; Engelhard, M. H.; Liu, J.; Aksay, I. A.; Lin, Y. Anal. Chem. 2010, 82, 2989-2995. doi:10.1021/ac100036p

11. Tajik, S.; Taher, M. A.; Beitollahi, H. Sens. Actuators, B 2014, 197, 228-236. doi:10.1016/j.snb.2014.02.096

12. Qiu, J.-D.; Liang, R.-P.; Wang, R.; Fan, L.-X.; Chen, Y.-W.; Xia, X.-H. Biosens. Bioelectron. 2009, 25, 852-857. doi:10.1016/j.bios.2009.08.048

13. Chen, M.; Diao, G. Talanta 2009, 80, 815-820. doi:10.1016/j.talanta.2009.07.068

14. Li, C.; Qiu, X.; Deng, K.; Hou, Z. Anal. Methods 2014, 6, 9078-9084. doi:10.1039/c4ay01838a

15. Mars, A.; Parolo, C.; Raouafi, N.; Boujlel, K.; Merkoçi, A. J. Mater. Chem. B 2013, 1, 2951-2955. doi:10.1039/c3tb20503g

16. Fan, L.; Zhang, Q.; Wang, K.; Li, F.; Niu, L. J. Mater. Chem. 2012, 22 , 6165-6170. doi:10.1039/c2jm15411k

17. Peng, H.; Huang, Z.; Zheng, Y.; Chen, W.; Liu, A.; Lin, X. J. Solid State Electrochem. 2014, 18, 1941-1949. doi:10.1007/s10008-014-2415-1

18. Liu, Y.; Xu, L.-P.; Wang, S.; Yang, W.; Wen, Y.; Zhang, X. Biosens. Bioelectron. 2015, 71, 396-400. doi:10.1016/j.bios.2015.04.068

19. Hezard, T.; Fajerwerg, K.; Evrard, D.; Collière, V.; Behra, P.; Gros, P. J. Electroanal. Chem. 2012, 664, 46-52. doi:10.1016/j.jelechem.2011.10.014

20. Dudin, P. V.; Unwin, P. R.; Macpherson, J. V. J. Phys. Chem. C 2010, 114, 13241-13248. doi:10.1021/jp1043706

21. Oesch, U.; Janata, L. Electrochim. Acta 1983, 28, 1237-1246. doi:10.1016/0013-4686(83)85011-7
22. Tremiliosi-Filho, G.; Dall'Antonia, L. H.; Jerkiewicz, G. J. Electroanal. Chem. 2005, 578, 1-8. doi:10.1016/j.jelechem.2004.12.007

23. Germain, P. S.; Pell, W. G.; Conway, B. E. Electrochim. Acta 2004, 49, 1775-1788. doi:10.1016/j.electacta.2003.12.009

24. Jurkschat, K.; Wilkins, S. J.; Salter, C. J.; Leventis, H. C.; Wildgoose, G. G.; Jiang, L.; Jones, T. G. J.; Crossley, A.; Compton, R. G. Small 2006, 2, 95-98. doi:10.1002/smll.200500129

25. Lan, M.; Chen, C.; Zhou, Q.; Teng, Y.; Zhou, H.; Niu, X. Adv. Mater. Lett. 2010, 1, 217-224.

26. Liu, H.-C.; Tsai, C.-C.; Wang, G.-J. Nanotechnology 2013, 24, 215101. doi:10.1088/0957-4484/24/21/215101

27. Neises, B.; Steglich, W. Angew. Chem., Int. Ed. Engl. 1978, 17, 522-524. doi:10.1002/anie.197805221

28. Li, D.; Li, J. Surf. Sci. 2003, 522, 105-111. doi:10.1016/S0039-6028(02)02334-8

29. Sahli, R.; Fave, C.; Raouafi, N.; Boujlel, K.; Schöllhorn, B.; Limoges, B. Langmuir 2013, 29, 5360-5368. doi:10.1021/la401117u

30. Eckermann, A. L.; Feld, J. D.; Shaw, J. A.; Meade, T. J. Coord. Chem. Rev. 2010, 254, 1769-1802. doi:10.1016/j.ccr.2009.12.023

31. Ruther, R. E.; Cui, Q.; Hamers, R. J. J. Am. Chem. Soc. 2013, 135, 5751-5761. doi:10.1021/ja312680p

32. Takeda, K.; Morita, T.; Kimura, S. J. Phys. Chem. B 2008, 112, 12840-12850. doi:10.1021/jp805711v

33. Warren, J. J.; Ener, M. E.; Vlček, A., Jr.; Winkler, J. R.; Gray, H. B. Coord. Chem. Rev. 2012, 256, 2478-2487. doi:10.1016/j.ccr.2012.03.032

34. Fan, C.; Plaxco, K. W.; Heeger, A. J. Proc. Natl. Acad. Sci. U. S. A. 2003, 100, 9134-9191. doi:10.1073/pnas.1633515100

35. Mayorga-Martinez, C. C.; Hlavata, L.; Miserere, S.; López-Marzo, A.; Labuda, J.; Pons, J.; Merkoçi, A. Biosens. Bioelectron. 2014, 55, 355-359. doi:10.1016/j.bios.2013.12.035

36. Mayorga-Martinez, C. C.; Pino, F.; Kurbanoglu, S.; Rivas, L.; Ozkan, S. A.; Merkoçi, A. J. Mater. Chem. B 2014, 2, 2233-2239. doi:10.1039/C3TB21765E

37. Anh, T. M.; Dzyadevych, S. V.; Van, M. C.; Renault, N. J.; Duc, C. N.; Chovelon, J.-M. Talanta 2004, 63, 365-370. doi:10.1016/j.talanta.2003.11.008

38. Şenel, M.; Çevik, E.; Abasıyanık, M. F. Sens. Actuators, B 2010, 145, 444-450. doi:10.1016/j.snb.2009.12.055

39. Tangkuaram, T.; Ponchio, C.; Kangkasomboon, T.; Katikawong, P.; Veerasai, W. Biosens. Bioelectron. 2007, 22, 2071-2078. doi:10.1016/j.bios.2006.09.011

40. Haddaoui, M.; Raouafi, N. Sens. Actuators, B 2015, 219, 171-178. doi:10.1016/j.snb.2015.05.023

41. Mohammed, R.; Ahmad, M.; Heng, L. Y. Sensors 2013, 13, 10014-10026. doi:10.3390/s130810014

42. Wang, H.-S.; Pan, Q.-X.; Wang, G.-X. Sensors 2005, 5, 266-276. doi:10.3390/s5040266

43. Zhang, L.; Liu, Y.; Chen, T. Int. J. Biol. Macromol. 2008, 43, 165-169. doi:10.1016/j.ijbiomac.2008.04.010

44. Wilson, M. S.; Rauh, R. D. Biosens. Bioelectron. 2004, 19, 693-699. doi:10.1016/S0956-5663(03)00275-6

45. Pereira, S. V.; Bertolino, F. A.; Fernández-Baldo, M. A.; Messina, G. A.; Salinas, E.; Sanz, M. I.; Raba, J. Analyst 2011, 136, 4745-4751. doi:10.1039/c1an15569e

46. Chen, H.; Jiang, J.-H.; Huang, Y.; Deng, T.; Li, J.-S.; Shen, G.-L.; Yu, R.-Q. Sens. Actuators, B 2006, 117, 211-218. doi:10.1016/j.snb.2005.11.026 
47. Lei, C.; Deng, J. Anal. Chem. 1996, 68, 3344-3349. doi:10.1021/ac960291n

48. Wang, L.; Wang, E. Electrochem. Commun. 2004, 6, 225-229. doi:10.1016/j.elecom.2003.12.004

49. Xiao, Y.; Ju, H.-X.; Chen, H.-Y. Anal. Chim. Acta 1999, 391, 73-82. doi:10.1016/S0003-2670(99)00196-8

50. Sánchez, P. D.; Miranda, A. J. M.; Costa-Garcia, A.; Tuñón Blanco, P. Electroanalysis 1991, 3, 281-285. doi:10.1002/elan.1140030407

51. Nakabayashi, Y.; Yoshikawa, H. Anal. Sci. 2000, 16, 609-613. doi:10.2116/analsci.16.609

52. Chang, Q.; Deng, K.; Zhu, L.; Jiang, G.; Yu, C.; Tang, H. Microchim. Acta 2009, 165, 299-305. doi:10.1007/s00604-008-0133-z

53. Ramakrishnan, S.; Pradeep, K. R.; Raghul, A.; Senthilkumar, R.; Rangarajanab, M.; Kothurkar, N. K. Anal. Methods 2015, 7, 779-786. doi:10.1039/c4ay02487g

\section{License and Terms}

This is an Open Access article under the terms of the Creative Commons Attribution License

(http://creativecommons.org/licenses/by/2.0), which permits unrestricted use, distribution, and reproduction in any medium, provided the original work is properly cited.

The license is subject to the Beilstein Journal of

Nanotechnology terms and conditions:

(http://www.beilstein-journals.org/bjnano)

The definitive version of this article is the electronic one which can be found at: doi:10.3762/bjnano.6.187 